Bulletin of Pharmaceutical Sciences
Assiut University
Website: http://bpsa.journals.ekb.eg/
e-mail: bullpharm@aun.edu.eg

\title{
CIRCULATING PATTERN OF RESPIRATORY VIRUSES, IN EGYPT, SEASON 2013-2014
}

Wael H. Roshdy ${ }^{1}$, Amel M. Naguib ${ }^{2}$, Ibrahim Elsayed ${ }^{3}$ and Yara I. Shamikh S, $^{4 *}$

${ }^{1}$ PhD in Biochemistry and Molecular Virology, Head of Tissue Culture and Virus Isolation, Central Public Health Laboratories, CPHL, Ministry of Health, Cairo 11613, Egypt

${ }^{2} \mathrm{MSc}$ in Clinical Pathology, Head of Virology Directorate, Central Public Health Laboratories, CPHL, Ministry of Health, Cairo 11613, Egypt

${ }^{3}$ Department of Biochemistry, Faculty of Science, Kafr Elsheikh University, Kafr Elsheikh 33784, Egypt

${ }^{4}$ Department of Microbiology and Immunology, Faculty of Pharmacy, Nahda University, BeniSuef 62513, Egypt

${ }^{5}$ Consultant, Virology Department, Egypt Centre for Research and Regenerative Medicine, ECRRM, Cairo 11517, Egypt

Respiratory viruses causes lower and upper respiratory tract infections; LRTIs and URTIs. These infections are from the predominant causes of infections, especially in children and infants.

Objective: This study, provides the evidence of using modern techniques as the multiplex PCR method, as a helpful tool in identifying the circulating pattern of respiratory viruses, in Egypt, thus this could help in identifying and inventing new treatment and vaccines.

Subjects and methods: A number of 237 nasopharyngeal aspirates, were collected between December 2013 to November 2014, from 2 Egyptian fever hospitals, classified into 3 groups; group 1; 37 normal persons, group 2; 100 patients with LRTIs or pneumatic group and group 3; 100 patients with URTIs or common cold group. The results were then assayed using multiplex RT-PCR, in the Central Public Health Laboratories, CPHL, Ministry of Health, Cairo, Egypt.

Results: Respiratory viruses, were detected in 152 cases, where the human rhinovirus was the most prominent; $15.6 \%$, followed by the respiratory syncytial virus, $10.5 \%$, metapneumovirus; $13 \%$, influenza-A (Flu-A); 6.3\%, adenovirus (AdV); 5.9\%, influenza-B (Flu-B); 5.4\%, parainfluenza-3 (PIV-3); $4 \%$ and a percentage of $0.42 \%$ infection for parainfluenza-1 (PIV-1), parainfluenza-2 (PIV-2) and human bocavirus (HBoV). No infections with parainfluenza-4, enterovirus nor the coronaviruses were detected. Both season and age of the patients, affect the detection rate of the analysis.

\section{INTRODUCTION}

Upper and lower respiratory tract viral infections; URTIs and LRTIs, are among the most common illness in humans, where children and infants bear the major burden of infection, typically presenting 3-5 episodes of respiratory tract infections ${ }^{1}$ or 5.06 episodes per child per year'. These infections have relation with significant patient morbidity and their related mortality ${ }^{3}$, thus, these infections, represent the main reason of death in children younger than five years of age worldwide and this accounts for 1.9 million to 2.2 million death globally ${ }^{4 \& 5}$ and an estimate of 2 million children under five years according to the World Health Organization (WHO), die of pneumonia, yearly ${ }^{6}$. Acute respiratory tract infections, are the most common cause for admitting children to hospital globally ${ }^{7}$ and 
febrile episodes in infants younger than three months of age ${ }^{8}$. Their infections are mainly of viral etiology, while the bacterial etiology represents only $10 \%$ of all URTIs with the subsequent $90 \%$ of infections caused by respiratory viruses ${ }^{9}$. Despite this viral etiological origin, antibiotics are often mistakenly prescribed in the treatment of URTIs, exacerbating ineffective treatments, antibiotic abuse and also bacterial resistance ${ }^{10}$.

Chronic co-morbidities or accompanied risk factors especially lung diseases like asthma or chronic obstructive pulmonary disease (COPD), increase the load of respiratory tract infections, especially in young ages or people with decreased immunity ${ }^{11 \& 12}$. The viruses primarily associated with URTIs commonly include rhinoviruses; HRV, enteroviruses; HEV, adenoviruses; AdV, parainfluenza viruses PIV; types 1, 2, 3 and 4, influenza viruses A and B (Flu-A and Flu-B), respiratory syncytial viruses; RSV and human coronaviruses $^{8,13 \& 14}$.

From the beginning of the $21^{\text {st }}$ century, nearly every year of the first decade, there was a newly discovered virus, which cause can respiratory diseases to human. In 2001, human metapneumovirus; hMPV, was discovered in the Netherlands, from family Paramyxoviridae $^{15}$. In the two following years, 2002-2003, a new human coronaviruses, known as Severe Acute Respiratory Syndrome coronavirus; SARS-CoV was discovered, in China $^{16}$. Then in 2004, another human coronavirus known as NL63; HCoV-NL63, was discovered, this time in Amsterdam ${ }^{17}$. Later in the following year, 2005, two more respiratory viruses were discovered, one from the Parvoviridae known as the human bocavirus; $\mathrm{HBoV}^{18 \& 19}$ and the other was from the Coronaviridae known as HKU1; HCoVHKU1, in Hong Kong ${ }^{20}$. The last discovered virus from the Coronaviridae was in 2012 and known as the Middle East Respiratory Syndrome coronavirus; MERS-CoV, and it was discovered in Saudi Arabia ${ }^{21}$. This discoveries introduced 6 new respiratory viruses, from the year 2001 till 2012, from which four of them were from the Coronaviridae, one from the Paramyxoviridae and one from the Parvoviridae.

Clinical differentiation between respiratory viruses is somehow difficult due to the similarity in their symptoms, either local as cough and rhinitis or systemic, as fever and headache. Also the influenza, in which its diagnosis has clinical bases, it is also inaccurate $^{22}$. The clinical manifestations or by symptoms differentiation can be applied only for young children, who can't discuss their symptoms, or how they feel. Knowing the cause or the etiology of the respiratory infection are of great need for establishing paediatric emergency department at hospitals or clinics, to propose the needed anti-influenza therapy ${ }^{23}$, and also to prevent nosocomial infection and to decrease the infection control methods, to get the most benefits of viral detection techniques, from lowering chest Xrays examination, other laboratory investigations and avoiding antibiotics overuse and better prognosis of the clinical routes of treatments ${ }^{24}$.

High sensitivity, short time in getting results and good availability, are the main advantages that makes polymerase chain reaction; PCR, the basic method in diagnosing respiratory viruses, in comparison to other conventional methods such as tissue culture ${ }^{25}$. The Multiplex reverse transcription; RT-PCR methods, allows detection of several viruses at the same time ${ }^{26}$, to overcome the any disadvantage of being performed in a laboratory or does not provide information timely for clinical decisions at the emergency department.

Point of care (POC) tests, are designed to be available directly at the place of patient care. This place must be accessible to staff who are not trained in laboratory, and provide quick results, to affect the clinical decision making ${ }^{27}$. These tests are frequently used for Influenza type A and B and also for the RSV. To carry out these tests, there is a need of working persons at the proper time and this is why the emergency department, practically use this test. This study will detail these newly discovered and emerging respiratory viruses and also will focus on influenza virus host interaction and possible treatments.

The aim of this study is to provide, a helpful tool; multiplex PCR method, for identification of the circulating pattern of respiratory viruses, in Egypt, thus help in improving and inventing the required vaccines, providing them with the most important strains 
according to the discovered results and investigating new treatment in accordance to the needs of our community, to respond to the identified viruses and thus decrease the health burden, hospitalization periods, and accompanied common co-morbidities and also provide each group of patients with a known infected virus with the proper handling methods, from hospitalization, ventilation, follow-up, .... etc.

\section{MATERIAL AND METHOD}

Two hundred and thirty seven patients were admitted to Imbaba and Menia fever hospitals, in Egypt, for one whole year, from December 2013 to November 2014, were included in our study. These patients were either with hypothetical diagnosis of an acute URTIs and LRTIs, or were undergoing surgical therapy. The diagnosis by the URTIs and LRTIs, was determined by doctors and physicians in these hospitals. The patients were then classified into three groups; Group 1 control; included 37 normal persons whom were underlying surgical therapy, Group 2; including 100 patients with LRTI or pneumatic group, and Group 3; including 100 patients with URTI or ILI; Influenza-like illness, or common cold symptoms group. The study was approved by the health research ethics committee and all tests were carried out in central public health laboratories (CPHL), Cairo, Egypt.

\section{Specimens}

Nasopharyngeal aspirate (NPA) samples were collected, in sterile vials; Nasopharyngeal Specimen Collection Flocked Swab, from each enrolled patient. According to the manufactures, this swabs were prepared using technology called nylon fibre and under specific condition of using fields of electrostatic power, and were provided by vertical flocking, which were finely fixed and were paired with the virus transport media tube; VTM, which provides safety in storage and transportation. For the samples to be taken from the patients, their head were tilted backward for a degree of about $70^{\circ}$, then horizontally tip were placed into one of the nose ditch, till the postal nasopharynx, then the stick rotated twice to allow the tip suck up sufficient aimed sample, then the swab was slowly pulled out and then put down instantly into the sterile VTM tube. The proper timing of collecting samples are between day one of illness and within two weeks. The VTM tubes containing the specimens, were kept on ice and handled during $2 \mathrm{hrs}$ of collection $^{28}$. All samples were anonymously labelled with specific study numbers and accessioning numbers, then stored at $-80^{\circ} \mathrm{C}$ until they are assayed. Clinical management and outcome data were collected.

\section{Group 1: Control group}

Thirty seven normal persons, who were underlying surgical therapy in Imbaba and Menia fever hospitals, with no respiratory tract symptoms, were our selected control group. Patients confirmed with respiratory infections within the 10 days before NPA collection, were excluded from the study.

\section{Group 2: LRTI (Pneumatic group)}

One hundred patients with LRTIs include pneumonia, defined according to WHO definitions, bronchitis and croup or severe pneumonia if there is drawing lower chest ${ }^{29}$. Symptoms of LRTIs usually involve runny nose, or its congestion, sore throat, and may be accompanied by cough, fever or lethargy and this symptoms changes by changing degree of infection from acute to severe infection.

\section{Group 3: URTIs or ILI or common cold group}

One hundred patients with UTRIs with symptoms vary from sinuses in the paranasal area, to systemic illness in pharynx and larynx. To recognize them from other URTI, after their exposure to respiratory viruses, with mean of 2 days, they have no cough, examined free from pharyngitis caused by Streptococcus for two weeks before the examination, have nasal congestion with or without sore throat, they have one weeks usually fever accompanied with acute sinusitis and conjunctivitis. The exclusion criteria was patients confirmed with LRTIs within 10 days prior to collection of $\mathrm{NPA}^{30 \& 31}$.

\section{Methods}

Multiplex RT-PCR technique was used for the detection of the respiratory ${ }^{32}$. This process 
was carried out at the division of medical virology, at the Central public health laboratories.

Thawing the samples at a temperature of $22^{\circ} \mathrm{C}$. On the automated QIA symphony platform (Qiagen, Germany) the extraction of the total nucleic acids was done utilizing the system's DSP virus/ Pathogen Mini Kit. The application protocol was carried out according to the instructions of QIA symphony, employing free 200V5 virus as the complex cell.

The 16 respiratory viruses, assayed in this research were amplified using the Multiplex RT-PCR and shown in table 1 . The instrument used was the real-time PCR machine Bio-Rad CFX96TM (Bio-Rad, Hercules, California, US) and according to (Seegene, South Korea) as a manufacture, the Anyplex II RV 16 assay was used. For this test, 100 copies/reaction were our lower limit of viral detection.

Table 1: Viruses tested with the Anyplex II detections System A set- B set.

\begin{tabular}{|c|c|c|c|}
\hline PIV4 & PIV1 & PIV2 & PIV3 \\
\hline AdV & Flu A & Flu B & HRVC \\
\hline hMPV & 229E & NL63 & RSV \\
\hline HBoV & HRV-B & HEV & HRV-A \\
\hline
\end{tabular}

Multiplex RT-PCR amplification for 16 commonly respiratory viruses causing infections; 14 different RNA viruses; Flu-A/B, PIV-1/2/3, RSV-A/B, HRVA/B/C, CoV-229E, NL69, HEV, hMPV and two different DNA viruses; HBov and $\mathrm{AdV}$, performed on the BioRad CFX96TM RT- PCR instrument, using the Anyplex II RV 16 assay (Seegene, South Korea) as per the manufacturer's recommendations. The reported lower limit of detection of this assay is 100 copies per reaction.

Respiratory virus detection reaction, are divided into two panels $\mathrm{A}$ and $\mathrm{B}$, where each detected nine targets (8 viruses and one internal control).

\section{Reverse transcription}

The extracted RNAs synthesize the cDNAs using cDNA Synthesis Premix (Seegene Inc. Soul, South Korea). All 237 samples were tested using Anyplex II RV16 (Seegene Inc., Soul, South Korea). Respiratory virus detection reaction, was divided into two panels $\mathrm{A}$ and $\mathrm{B}$, where each detected nine targets ( 8 viruses and one internal control), 14 different RNA viruses; Flu-A/B, PIV-1/2/3, RSV-A/B， HRV-A/B/C， CoV-229E， NL69, HEV, hMPV and two different DNA viruses; $\mathrm{HBoV}$ and AdV. The technologies of DPOTM and TOCETM are used by the multiplex PCR technique to identify and differentiate the 16 respiratory viruses. The RT-PCR instrument ends the process with melting curve analyses. Anyplex II RV16 detects: Flu-A, Flu-B, PIV1/2/3, RSV-A/B, AdV, HRV A/B/C, CoV 229E, NL69, HEV, hMPV and HBoV.

The viruses were identified on the CFX96 instrument, by the amplicon specific melting temperature and one of the four fluorophores labelling. Seegene Viewer software analysed the results of this amplification.

\section{Reverse transcription procedure}

- $8 \mu \mathrm{l}$ of the extracted nucleic acid, $0.2 \mu \mathrm{g}$ random hexamers, and $3 \mu 1$ nuclease-free water were added to a sterile, nuclease-free tube on ice.

- The tube was incubated at $80^{\circ} \mathrm{C}$ for 3 mins in a Bio-Rad CFX96TM real-time PCR instrument (Bio-Rad, Hercules, California, US), chilled on ice for 2 mins and spun down briefly in a Spectrafuge Mini Centrifuge (Lab net International, New Jersey, USA).

- For a $20 \mu \mathrm{l}$ final reaction volume, $4 \mu 15 \mathrm{X}$ reaction buffer plus $1 \mu 1$ Ribolock $^{\mathrm{TM}}$ RNase inhibitor $(20 \mathrm{u} / \mu \mathrm{l})$ plus $2 \mu \mathrm{l} 10 \mathrm{mM}$ dNTP mix plus $1 \mu 1$ Revert Aid $^{\mathrm{TM}}$ M-MuLV Reverse Transcriptase $(200 \mathrm{u} / \mu \mathrm{l})$ were added to the tube.

- The tube was incubated twice. The first time was at $37^{\circ} \mathrm{C}$ for $90 \mathrm{~min}$. The second time was at $94^{\circ} \mathrm{C}$ for only 2 mins in a Bio-Rad CFX96TM real-time PCR instrument (BioRad, Hercules, California, US).

- The tube was chilled on ice for 2 mins and spun down briefly in a Spectrafuge Mini Centrifuge before storage at $-20^{\circ} \mathrm{C}$ until amplification process.

\section{Amplification}

All samples were amplified at the same time, each one in three separate reactions (Set $\mathrm{A}, \mathrm{B}$, and $\mathrm{C}$ ). The content of each reaction is listed in table 2 and 3, showing the Anyplex ${ }^{\circledR}$ RV16 PCR reagent volume and the cycling and amplification protocol for multiplex real time PCR reaction, respectively. 


\section{RESULTS AND DISCUSSION}

\section{Results}

\section{Study groups}

152 viruses in the total 237 (group 1; control, group 2; LTRI and group 3; URTI) tested specimens were detected with a percent of $64.1 \%$ of the total samples studied. Single infections were 103 while multiple infections were 49. The highest infection was for the HRV, which was detected in 37 samples and divided into 26 single infection and 11 coinfection, followed by the RSV with 36 positive cases, followed by the rest of the respiratory viruses, except for the PIV-4, HEV and the human coronaviruses which were not detected in all the tested specimens.

Table 2: Anyplex ${ }^{\circledR}$ RV16 PCR reagent volume.

\begin{tabular}{|c|c|c|}
\hline Reagent & Content & Volume $(\mu \mathrm{l})$ \\
\hline \multirow[t]{3}{*}{ 5X RV16 PM } & $\begin{array}{l}\text { - Primer pairs for pathogens in each } \\
\text { set }(\mathrm{A}, \mathrm{B} \text { or } \mathrm{C})\end{array}$ & \multirow[t]{3}{*}{5} \\
\hline & - Primer pair for internal control & \\
\hline & - Template for internal control & \\
\hline RNase free water & $\begin{array}{l}\text { 8-methoxypsoralen (8-MOP) to } \\
\text { prevent carry-over contamination }\end{array}$ & 2 \\
\hline \multirow{3}{*}{$\begin{array}{l}\text { 4X Anyplex PCR master } \\
\text { mix (with UDG) }\end{array}$} & - DNA polymerase & \multirow[t]{3}{*}{5} \\
\hline & - Buffer containing dNTPs & \\
\hline & $-\mathrm{MgCl}_{2}$ and stabilisers & \\
\hline Nucleic acid sample & & 8 \\
\hline Total volume & & 20 \\
\hline
\end{tabular}

Table 3: Cycling and amplification protocol for multiplex Real Time PCR reaction.

\begin{tabular}{|c|c|c|c|}
\hline Segment & No. of cycles & Temperature & Duration \\
\hline 1 & 1 & $50^{\circ} \mathrm{C}$ & $4 \min$ \\
\hline 2 & 1 & $95^{\circ} \mathrm{C}$ & $15 \mathrm{~min}$ \\
\hline 3 & \multirow[t]{3}{*}{30} & $95^{\circ} \mathrm{C}$ & $0.5 \mathrm{~min}$ \\
\hline 4 & & $60^{\circ} \mathrm{C}$ & $1.0 \mathrm{~min}$ \\
\hline 5 & & $72^{\circ} \mathrm{C}$ & $0.5 \mathrm{~min}$ \\
\hline 6 & 1 & $55^{\circ} \mathrm{C}$ & $0.5 \mathrm{~min}$ \\
\hline 7 & 1 & \multicolumn{2}{|c|}{ Melting curve $55^{\circ} \mathrm{C}-85^{\circ} \mathrm{C}\left(5 \mathrm{~s} / 0.5^{\circ} \mathrm{C}\right)$} \\
\hline 8 & \multirow[t]{3}{*}{10} & $95^{\circ} \mathrm{C}$ & $0.5 \mathrm{~min}$ \\
\hline 9 & & $60^{\circ} \mathrm{C}$ & $1.0 \mathrm{~min}$ \\
\hline 10 & & $72^{\circ} \mathrm{C}$ & $0.5 \mathrm{~min}$ \\
\hline 11 & 1 & $55^{\circ} \mathrm{C}$ & $0.5 \mathrm{~min}$ \\
\hline 12 & 1 & \multicolumn{2}{|c|}{ Melting curve $55^{\circ} \mathrm{C}-85^{\circ} \mathrm{C}\left(5 \mathrm{~s} / 0.5^{\circ} \mathrm{C}\right)$} \\
\hline 13 & \multirow[t]{3}{*}{10} & $95^{\circ} \mathrm{C}$ & $0.5 \mathrm{~min}$ \\
\hline 14 & & $60^{\circ} \mathrm{C}$ & $1.0 \mathrm{~min}$ \\
\hline 15 & & $72^{\circ} \mathrm{C}$ & $0.5 \mathrm{~min}$ \\
\hline 16 & 1 & $55^{\circ} \mathrm{C}$ & $0.5 \min$ \\
\hline 17 & 1 & \multicolumn{2}{|c|}{ Melting curve $55^{\circ} \mathrm{C}-85^{\circ} \mathrm{C}\left(5 \mathrm{~s} / 0.5^{\circ} \mathrm{C}\right)$} \\
\hline
\end{tabular}


No respiratory viruses were detected in 85 specimens, giving a ratio of $35.9 \%$ negative cases. To identify and provide the required collective data, about the most circulating strains of respiratory viruses either causing LRTIs, URTIs or even asymptomatic persons and thus propose the required strains to be included in vaccines and suggest investigating new drugs for the discovered strains, in Egypt, the numbers and percentages of the detected viruses are shown in (Table 4).

\section{Group 1: Control group}

Eight samples, with positive respiratory viruses, were detected in control group in the asymptomatic patients so, we decided to include these sample to the study groups, as it is important to indicate the total prevalence rate of respiratory viruses, in Egypt.

\section{Group 2: LRTI (Pneumatic group)}

The numbers and percentages of the detected viruses in group 2 are shown in (Table $5)$.

Table 4: Viruses detected in single and multiple infections in all three groups; Group 1, 2 and 3, by multiplex RT-PCR.

\begin{tabular}{|l|c|c|c|c|c|c|c|c|c|c||}
\hline \multirow{3}{*}{$\begin{array}{c}\text { Total } \\
\text { groups }\end{array}$} & HRV & RSV & hMPV & Flu-A & AdV & Flu-B & PIV-3 & PIV-1 & PIV-2 & HBoV \\
\cline { 2 - 11 } & $\mathrm{N}-37$, & $\mathrm{N}-36$, & $\mathrm{N}-25$, & $\mathrm{N}-15$, & $\mathrm{N}-14$, & $\mathrm{N}-13$, & $\mathrm{N}-9$, & $\mathrm{N}-1$, & $\mathrm{N}-1$, & $\mathrm{N}-1$, \\
& $15.6 \%$ & $15.1 \%$ & $10.5 \%$ & $6.3 \%$ & $5.9 \%$ & $5.4 \%$ & $4 \%$ & $0.42 \%$ & $0.42 \%$ & $0.42 \%$ \\
\hline HRV & 26 & 4 & 3 & 1 & 2 & 1 & 0 & 0 & 0 & 0 \\
\hline RSV & 4 & 26 & 1 & 1 & 1 & 2 & 1 & 0 & 0 & 0 \\
\hline hMPV & 3 & 1 & 18 & 1 & 2 & 0 & 0 & 0 & 0 & 0 \\
\hline Flu-A & 1 & 1 & 1 & 11 & 0 & 1 & 0 & 0 & 0 & 0 \\
\hline AdV & 2 & 1 & 2 & 0 & 7 & 1 & 1 & 0 & 0 & 0 \\
\hline Flu-B & 1 & 2 & 0 & 1 & 1 & 7 & 1 & 0 & 0 & 0 \\
\hline PIV-3 & 0 & 1 & 0 & 0 & 1 & 1 & 6 & 0 & 0 & 0 \\
\hline PIV-1 & 0 & 0 & 0 & 0 & 0 & 0 & 0 & 1 & 0 & 0 \\
\hline PIV-2 & 0 & 0 & 0 & 0 & 0 & 0 & 0 & 0 & 1 & 0 \\
\hline HBoV & 0 & 0 & 0 & 0 & 0 & 0 & 0 & 0 & 0 & 1 \\
\hline
\end{tabular}

$\mathrm{N}$ : Represent number of positive samples for each virus.

$\%$ : Represent the proportion of positive samples of each virus, from the total number of samples tested; 237 samples.

Triple infections which were detected in the study: HRV/RSV/AdV $>2$.

HRV/RSV/FLU-A $\rightarrow 3 \quad$ HRV/RSV/FLU-B $\rightarrow 2 \quad$ RSV/AdV/PIV-3 $\rightarrow 1 \quad$ HRV/ hMPV /Adv $\rightarrow 1$

Table 5: Viruses detected in single and multiple infections in group 2; pneumatic group.

\begin{tabular}{|l|c|c|c|c|c|c|c|c|c|c||}
\hline \multirow{2}{*}{$\begin{array}{c}\text { Total } \\
\text { groups }\end{array}$} & HRV & RSV & hMPV & Flu-A & AdV & Flu-B & PIV-3 & PIV- 1 & PIV-2 & HBoV \\
\cline { 2 - 12 } & N-17, 17.0\% & N-15, 14\% & N-13, 13\% & N-3,3\% & N-1, 1\% & N-1, 1\% & N-7, 7\% & N-0, 0\% & N-1, 1\% & N-1, 1\% \\
\hline HRV & 14 & 2 & 1 & 0 & 0 & 0 & 0 & 0 & 0 & 0 \\
\hline RSV & 2 & 13 & 0 & 0 & 0 & 0 & 0 & 0 & 0 & 0 \\
\hline hMPV & 1 & 0 & 12 & 0 & 0 & 0 & 0 & 0 & 0 & 0 \\
\hline Flu-A & 0 & 0 & 0 & 3 & 0 & 0 & 0 & 0 & 0 & 0 \\
\hline AdV & 0 & 0 & 0 & 0 & 1 & 0 & 0 & 0 & 0 & 0 \\
\hline Flu-B & 0 & 0 & 0 & 0 & 0 & 1 & 0 & 0 & 0 & 0 \\
\hline PIV-3 & 0 & 0 & 0 & 0 & 0 & 0 & 7 & 0 & 0 & 0 \\
\hline PIV-1 & 0 & 0 & 0 & 0 & 0 & 0 & 0 & 0 & 0 & 0 \\
\hline PIV-2 & 0 & 0 & 0 & 0 & 0 & 0 & 0 & 0 & 1 & 0 \\
\hline HBoV & 0 & 0 & 0 & 0 & 0 & 0 & 0 & 0 & 0 & 1 \\
\hline
\end{tabular}

$\mathrm{N}$ : Represent number of positive samples for each virus.

$\%$ : Represent the proportion of positive samples of each virus, from the total number of samples tested of this group (100 patients). 
17 cases infected with HRV (14 single infection and 3 mixed infection) were found in the pneumatic group, 15 cases infected with RSV (13 single and 2 mixed infection with HRV), 13 infection with hMPV (only 1 mixed infection with the HRV), 7 cases in PIV-3, 3 cases in Flu-A, 1 case only in PIV-2, Flu-B, $\mathrm{HBoV}$ and AdV PIV-3. No infections with PIV-1, PIV-4, HEV nor the human coronaviruses were detected in the tested specimens for this group.

\section{Group 3: URTIs or ILI or common cold group}

The numbers and percentages of the detected viruses in group 3 are shown in (Table 6). 47 mixed infection and 5 triple infections were found in the URTIs or the common cold group. The highest number of infection was detected in RSV with 17 infected cases (10 single and 7 mixed infections), followed by the HRV with 15 infected cases (11 single and 4 mixed cases), 13 cases in both AdV and Flu-B, 12 cases in both hMPV and Flu-A, 2 cases in PIV-3 and only 1 case in PIV-1. No infections with PIV-2, PIV-4, HBoV, HEV nor the human coronaviruses were detected in the tested specimens for this group.
Demographic characteristics, clinical picture, gender, admission department and outcome of study samples, including HRV positive samples and subtypes

HRV infections were detected in 37 patients representing $15.6 \%$. HRV-A was the most widespread species, where 19 out of 37 were HRV-A infected, representing $51.35 \%$, followed by HRV-C, with 14 out of 37 , representing $37.8 \%$ then the HRV-B species with 4 out of 37 , representing $10.8 \%$. From the total number of all the HRV species' infections, there were 32 patients only with available age information. The age range for was between 0.01 and 81 years. The mean age was 20.9 with standard deviation 23.9 and median equals to 7 . Demographic analysis indicated that $20.6 \%$ of the total population was less than two years of age. The overall rate of the age group $<2$ years was greater than the other age groups, especially for HRV-A and HRV-C infections. HRV was detected more in males (63\%) especially in HRV-A and HRV-C infections also, showing that gender might be considered also as a risk factor for HRV infections. Dyspnea and abnormal breathing sounds, are major symptoms of HRV infection and which were found in all the HRV-B cases. For the total study population about the hospitalized percent was $61.8 \%$ and this was at the ICU, from the total HRV cases, the hospitalized patients in the ICU were 58.9\%. (Table 7).

Table 6: Viruses detected in single and multiple infections in group 3, URTIs or ILI or common cold group.

\begin{tabular}{|l|c|c|c|c|c|c|c|c|c|c|}
\hline \multirow{2}{*}{$\begin{array}{c}\text { Total } \\
\text { groups }\end{array}$} & HRV & RSV & hMPV & Flu-A & AdV & Flu-B & PIV-3 & PIV-1 & PIV-2 & HBoV \\
\cline { 2 - 12 } & N-15, 15\% & $\mathrm{N}-17,17 \%$ & $\mathrm{~N}-12,12 \%$ & $\mathrm{~N}-12,12 \%$ & $\mathrm{~N}-13,13 \%$ & $\mathrm{~N}-13,13 \%$ & $\mathrm{~N}-2,2 \%$ & $\mathrm{~N}-1,1 \%$ & $\mathrm{~N}-0,0 \%$ & $\mathrm{~N}-0,0 \%$ \\
\hline HRV & 11 & 1 & 2 & 1 & 2 & 1 & 0 & 0 & 0 & 0 \\
\hline RSV & 1 & 10 & 1 & 1 & 1 & 2 & 1 & 0 & 0 & 0 \\
\hline hMPV & 0 & 1 & 6 & 1 & 2 & 0 & 0 & 0 & 0 & 0 \\
\hline Flu-A & 1 & 1 & 1 & 8 & 0 & 1 & 0 & 0 & 0 & 0 \\
\hline AdV & 1 & 1 & 2 & 0 & 6 & 1 & 1 & 0 & 0 & 0 \\
\hline Flu-B & 1 & 2 & 0 & 1 & 1 & 7 & 0 & 0 & 0 & 0 \\
\hline PIV-3 & 0 & 1 & 0 & 0 & 1 & 1 & 2 & 0 & 0 & 0 \\
\hline PIV-1 & 0 & 0 & 0 & 0 & 0 & 0 & 0 & 1 & 0 & 0 \\
\hline PIV-2 & 0 & 0 & 0 & 0 & 0 & 0 & 0 & 0 & 0 & 0 \\
\hline HBoV & 0 & 0 & 0 & 0 & 0 & 0 & 0 & 0 & 0 & 0 \\
\hline \hline
\end{tabular}

$\mathrm{N}$ : Represent number of positive samples for each virus.

$\%$ : Represent the proportion of positive samples of each virus, from the total number of samples tested of this group (100 patients). 
Table 7: Demographic characteristics, clinical picture, gender, admission department and outcome of study samples, including HRV positive samples and subtypes.

\begin{tabular}{|c|c|c|c|c|c|}
\hline Age groups (years) & \begin{tabular}{|c|} 
Total Study \\
population $(\%)$
\end{tabular} & Total HRV & HRV-A & HRV-B & HRV-C \\
\hline$<2$ & $20.6 \%^{\mathrm{a}}$ & $26.3 \%^{\mathrm{b}}$ & $29.8 \%$ & $5.3 \%$ & $26.9 \%$ \\
\hline $2-$ & $13.8 \%$ & $17.5 \%$ & $15.5 \%$ & $10.5 \%$ & $25 \%$ \\
\hline $5-$ & $5.7 \%$ & $8.8 \%$ & $9.5 \%$ & $5.3 \%$ & $7.7 \%$ \\
\hline $10-$ & $5.2 \%$ & $8.8 \%$ & $9.5 \%$ & $0 \%$ & $11.5 \%$ \\
\hline $20-$ & $9.6 \%$ & $8.1 \%$ & $4.8 \%$ & $31.6 \%$ & $5.8 \%$ \\
\hline $30-$ & $8.5 \%$ & $4.4 \%$ & $3.6 \%$ & $0 \%$ & $7.7 \%$ \\
\hline $40-$ & $8.1 \%$ & $6.3 \%$ & $4.8 \%$ & $15.8 \%$ & $3.8 \%$ \\
\hline $50-$ & $13.3 \%$ & $10.6 \%$ & $11.9 \%$ & $10.5 \%$ & $9.6 \%$ \\
\hline$\geq 60$ & $15.1 \%$ & $9.4 \%$ & $10.7 \%$ & $21.1 \%$ & $1.9 \%$ \\
\hline Total: N (\%) & $237(100 \%)$ & $37(100 \%)$ & $19(100 \%)$ & $4(100 \%)$ & $19(100 \%)$ \\
\hline \multicolumn{6}{|c|}{ Gender } \\
\hline Male & $59 \%^{\mathrm{c}}$ & $63 \%^{\mathrm{d}}$ & $66 \%{ }^{d}$ & $45 \%$ & $64 \%{ }^{\mathrm{e}}$ \\
\hline Female & $41 \%$ & $37 \%$ & $34 \%$ & $55 \%$ & $36 \%$ \\
\hline Total: N (\%) & $237(100 \%)$ & $37(100 \%)$ & $19(100 \%)$ & $4(100 \%)$ & $14(100 \%)$ \\
\hline \multicolumn{6}{|c|}{ Clinical Picture } \\
\hline Dyspnea $^{\mathbf{e}}$ & $90.5 \%$ & $88.3 \%$ & $80.4 \%$ & $100 \%$ & $96.2 \%$ \\
\hline Abnormal Breathsound $^{\mathrm{e}}$ & $79.4 \%$ & $83.6 \%$ & $78.3 \%$ & $100 \%$ & $84.9 \%$ \\
\hline Tachypnea & $58.5 \%$ & $99(57.9 \%)$ & $48.9 \%$ & $75 \%$ & $67.9 \%$ \\
\hline Sputum & $63.4 \%$ & $93(54.4 \%)$ & $54.3 \%$ & $60 \%$ & $52.8 \%$ \\
\hline Sore throat & $49.6 \%$ & $79(46.2 \%)$ & $47.8 \%$ & $55 \%$ & $39.6 \%$ \\
\hline Chest Pain & $4.5 \%$ & $8(4.7 \%)$ & $4.3 \%$ & $5 \%$ & $5.7 \%$ \\
\hline Hemoptysis & $2.5 \%$ & $5(2.9 \%)$ & $2.2 \%$ & $0 \%$ & $5.7 \%$ \\
\hline Total: N (\%) & $237(100 \%)$ & $37(100 \%)$ & $19(100 \%)$ & $4(100 \%)$ & $14(100 \%)$ \\
\hline \multicolumn{6}{|c|}{ Admission Department } \\
\hline ICU & $147\left(61.8 \%{ }^{\mathrm{f}}\right)$ & $22\left(58.9 \%^{\mathrm{g}}\right)$ & $11(59.3 \%)$ & $3(75 \%)$ & $8(57 \%)$ \\
\hline Pediatrics & $23.9 \%$ & $28.6 \%$ & $26.4 \%$ & $5 \%$ & $43.1 \%$ \\
\hline Medical Ward & $14.3 \%$ & $12.5 \%$ & $14.3 \%$ & $25 \%$ & $2 \%$ \\
\hline Total: N (\%) & $237(100 \%)$ & $37(100 \%)$ & $19(100 \%)$ & $4(100 \%)$ & $14(100 \%)$ \\
\hline \multicolumn{6}{|c|}{ Outcome } \\
\hline Discharge & $74.3 \%$ & $71.7 \%$ & $58(66.7 \%)$ & $12(66.7 \%)$ & $40(81.6 \%)$ \\
\hline Transfer & $20 \%$ & $22 \%$ & $22(25.3 \%)$ & $5(27.8 \%)$ & $7(14.3 \%)$ \\
\hline Death & $4.2 \%$ & $16.2 \%$ & $4(10.8 \%)$ & $1(5.6 \%)$ & $1(2.7 \%)$ \\
\hline Unknown & $1.6 \%$ & $2.5 \%$ & $3(3.4 \%)$ & $0(0 \%)$ & $1(2 \%)$ \\
\hline Total: N (\%) & $237(100 \%)$ & $37(100 \%)$ & $19(100 \%)$ & $4(100 \%)$ & $14(100 \%)$ \\
\hline
\end{tabular}

$\mathrm{N}$ : Represent number of positive samples for each virus

$\%$ : Represent the proportion of positive samples of each virus from the total number of samples tested of this group.

Clinical data collected from questionnaire.

${ }^{a}$ For study population: $20.6 \%$ of total populations are less than two years of age.

${ }^{b}$ For total HRV: Children under two years of age are infected with $26.3 \%$ of total HRV infections.

${ }^{\mathrm{c}}$ Males represent $59 \%$ of the total study populations.

${ }^{\mathrm{d}}$ About two third of total HRV infections are among males; 63\%, similarly, HRV-A and HRV-C while only $45 \%$ of HRV-B are among males.

${ }^{\mathrm{e}}$ Dyspnea and abnormal breathing sounds are major symptoms of HRV infection which reaches up to $100 \%$ in HRV-B infection.

${ }^{\mathrm{f}}$ For study population: $61.8 \%$ were admitted to the ICU.

${ }^{\mathrm{g}}$ For total HRV cases: $58.9 \%$ were admitted to the ICU. 
HRV infection, was found in the pneumatic group and was represented all year around especially, between January to April and then between August to December, where HRV-A infection was the most predominant type, between January to April then between August and September with the exception of December where HRV-C was the prevalent type. HRV-B was mostly detected between July and December. HRV monthly distribution percentages is shown in figure 1 .

\section{Correlation between human rhinovirus species and pneumatic group (LRTIs)}

In the common cold or URTIs group, there were significant correlations between HRV-A and HRV-C and pneumonia, with $\mathrm{R}$ values of $0.08(p=0.037, p<0.05)$ and $0.20(p<0.001)$, respectively (Table 8). No significant correlation was identified for HRV-A, -B, and $\mathrm{C}$ infections between the pneumatic group and the control group $(p>0.05)$.

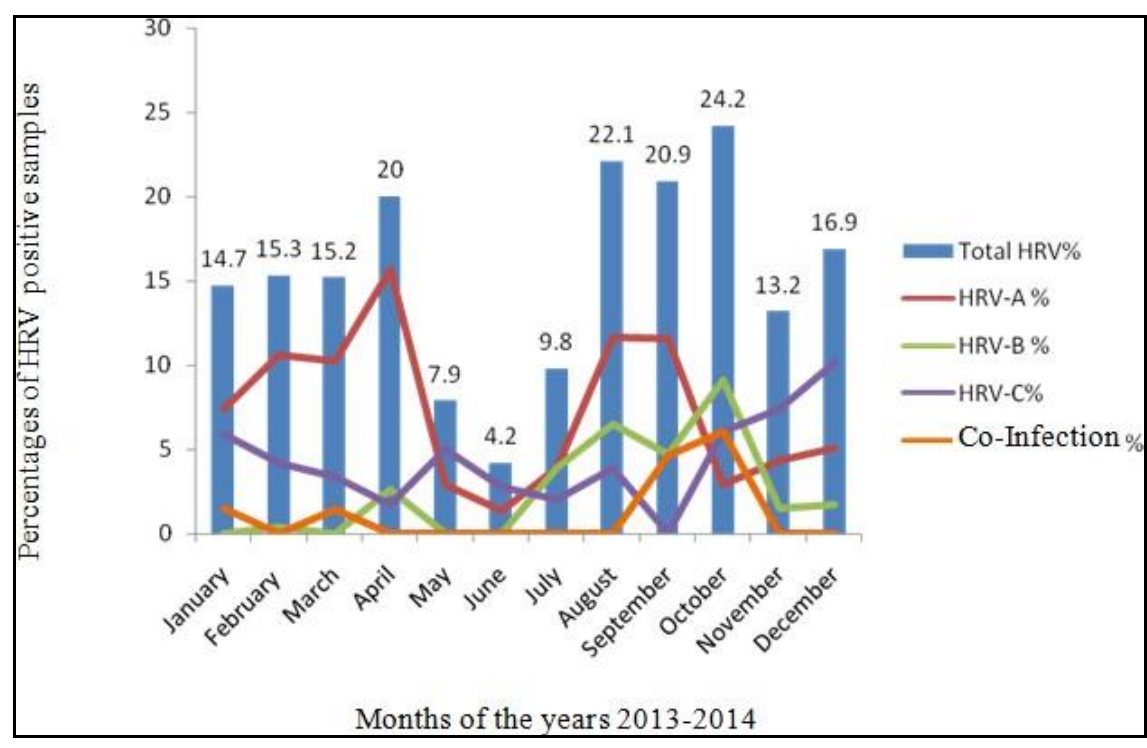

Fig. 1: Percentages of HRV types detected by month.

Total HRV percentage/month is indicated over the corresponding bar.

Table 8: Correlation between human rhinovirus species and pneumatic group.

\begin{tabular}{||c|c|c|c||}
\hline $\begin{array}{c}\text { Groups compared with } \\
\text { pneumonia group }\end{array}$ & HRV species P & Spearman's R & $P$ \\
\hline Control group $(n=37)$ & HRV-A $(n=2)$ & 0.031 & 0.622 \\
& HRV-B $(n=1)$ & 0.101 & 0.12 \\
& HRV-C $(n=2)$ & 0.095 & 0.161 \\
\hline Common cold UTRIs group & HRV-A $(n=7)$ & 0.082 & 0.037 \\
$(n=100)$ & HRV-B $(n=1)$ & 0.019 & 0.98 \\
& HRV-C $(n=7)$ & 0.202 & $<0.01$ \\
\hline
\end{tabular}

In the common cold or URTIs group, there were significant correlations between HRV-A and HRV-C and pneumonia, with $\mathrm{R}$ values of $0.08(p=0.037, p<0.05)$ and $0.20(p<0.001)$, respectively (Table 8$)$. No significant correlation was identified for HRV A, B, and C infections between the pneumonia group and control group $(p>0.05)$. 


\section{Discussion}

In the present study, the Seegene Inc., Soul, invented technology, known as the DPOTOCE, was used to describe the operating and specific detection of sixteen respiratory viruses, at the same time ${ }^{33}$. We compare our results to many other published studies in a number of different countries, the RSV was the most common virus in patients complaining from LRTIs $^{14}$, followed by adenovirus ${ }^{34}$ and influenza viruses $\mathrm{H} 3 \mathrm{~N} 2$ and $\mathrm{H} 1 \mathrm{~N} 1^{35}$ in 2012 and was published in western Europe, in the same year same results were published also in Africa in Ghana ${ }^{36}$ and in an earlier year in 2011, was published in Egypt ${ }^{37}$. This was in contrast to our findings, where the most recurrent virus was the HRV are (15.6\%), followed by the RSV, the hMPV and then the influenza viruses. But our results were similar to other studies which judge the HRV as an major cause of respiratory tract infection ${ }^{38 \& 39}$ and which induce wheezing and aid in worsening of asthma ${ }^{40}$. Single infection with HRV was found in $10(4.21 \%)$ samples and coinfection was found in $26(10.9 \%)$ samples. HRV represents the chief cause of severe acute respiratory tract infections; SARI, for all age population and represents $24.3 \%$ of cases in which a virus was detected.

Males and young children were the majority of the patients whom were admitted to hospital, as found in other studies ${ }^{41}$. One week was the median period of staying in hospitals; this is compatible with other published papers in other countries and continents as Eastern Europe, Ghana in Africa and in Asia in both Saudi Arabia and the United Arab Emirates, respectively ${ }^{35,36,42 \& 43}$.

Highest co-infection rate was found with RSV in 4 cases $(10.8 \%)$. This finding is concurrent with other reports ${ }^{44}$. Following the RSV in number of co-infection, was the hMPV with 3 co-infection cases (8.9\%), in which two cases from them $(66 \%)$ were paediatrics admitted to the ICU. Same results was published by other studies ${ }^{45}$. Low co-infection rate with influenza viruses, was noticed in our study, where only two cases $(7.7 \%)$ were detected. This is consistent with other reports, stating that the increase in the pandemic influenza virus, could be obstructed because of infection with $\mathrm{HRV}^{46 \& 47}$.
In our study, HRV-A and HRV-C were found in $18(50.5 \%)$ and $12(31 \%)$ patients representing 12 and 8 types of each, respectively. However, we detected HRV-B from only $4(10.8 \%)$ patients representing 4 types of HRV-B. So, HRV-C was found with a frequency less than that of HRV-A, but greater than that of HRV-B and this also occurred in other studied populations ${ }^{48}$.

A large number of circulating types of rhinovirus was discovered till now ${ }^{49}$, within our study we discovered the HRV-C, in the subject population from 7 sites all over Egypt. These results are concurrent with Wisdom et al. ${ }^{50}$.

In our study, the more severe illness were associated with HRV-A infection than the HRV-C, where it represented four out of each six fatal cases. Our results were opposite to other published papers as in Longtin et al. ${ }^{51}$, in which that HRV-C species was suggested as the more severe and pathogenic species, than the other HRV species ${ }^{48,52 \& 53}$.

Difference in the age distributions, was not our aim from our study but the clinical and epidemiological information collected from patients, provided important findings in this filed. The age profile for HRV-A and HRV-C infection were similar but HRV-B was found more in older age groups (>21 years old). In our study group, HRV-A and HRV-C were over examplificated significantly in males than in females where in males, HRV-A and HRV-C infections were found approximately two third that in females. This finding is in contrast with what was found by others ${ }^{50}$.

Larger sample number, over a longer period of time and across a larger number of governorates, is recommended for further studies.

Oxygen supplement was required for influenza patients with any type of respiratory tract infection, than the non-influenza patients, as published in other studies ${ }^{7}$. All over the year, UTRI and LRTIs took place in our study and in other countries, as in the United Arab Emirates $^{43}$, but these infections were higher common in autumn and winter in India, and extent in July and August during the season of rain not all over the year ${ }^{54}$. In our study, comorbidity with heart diseases was frequent for LRTIs patients who stayed in hospitals. This is in contrast to other studies that stated that the heart, the nervous system and the 
neuromuscular diseases cardiac, are not considered as risk factors for long stay in hospitals, among positive influenza patients ${ }^{55 \& 56}$. This may be due to geographical differences, differences in pathogens or differences methods of diagnosis instead of the design of the study or the methods used in them.

Lower age mean was discovered in the RSV cases than the non-RSV cases, with $64 \%$ of them younger than 6 months old. In many studies, the young age was reported as a risk factor for RSV infection ${ }^{57}$. Some studies associated this to the decrease in the cellular immunity $^{58}$, and the decrease in maternal antibodies acquired from their mothers, attributed with decrease in the humoral immune response magnitude to RSV, in patients aged $<3$ months $^{59}$. Cough and difficulty in breathing was chronic and happened in almost all LRTIs patients, in our study. We observed higher respiratory rates, in RSV patients, especially in patients younger than one year in old; $80 \%$ of the RSV cases; this was also observed by other studies ${ }^{60}$.

Determining the geographical distribution of RSV infection, is a useful tool for guess the probability of epidemics and design control and preventive methods, especially for the high risk groups. The highest hospitalization rate of RSV infection was demonstrated in our study (3 times greater than other etiologies, $p<0.001$ ), which is consistent with other studies ${ }^{61}$ and the highest one require oxygen supplementation. This cases also have higher fatality rate, but this may be due to the small number of deaths, that may make a clinically significant comparison. Prematurity, diseases in lung and heart, are also among the familiar risk factors attributed to RSV infection.

We need a fast, precise and cheap diagnostic tool, for diagnosing respiratory viruses, to control and prevent the annual influenza and other circulatory respiratory viruses.

Two studies cited the incidence of viral respiratory viruses in Egypt. The first study was published 2016, and was from June 2009 till December 2013, on 6113 patients, in Damanhur, showed a $67 \%$ incidence rate in patients less than one year and $19 \%$ incidence rate in patients over 65 years of age ${ }^{62}$.
The second study, which was published 2019 and was done from the period 2010-2014, at Cairo University Hospital, showed an incidence rate viral respiratory viruses in Egypt of $33.5 \%$ in hospitalized adult and paediatric Egyptian patients with $\mathrm{SARI}^{63}$.

\section{Conclusion}

The circulating pattern of respiratory viruses epidemiology, demonstrated that the HRV were the most common one followed by the RSV, the hMPV and then the influenza viruses. HRV-A might be linked to more severe illness than HRV-C, with nearly similar age profile, in contrast to HRV-B which was found more in older age groups ( $>21$ years old). Thus when providing HRV vaccine, the main strain to be included in the vaccine, especially for children, should be HRV-A, also, new drugs must be investigated, prescribed and licensed for HRV-A.

While in infections with RSV, most cases were severe, with high hospitalization rate, with significantly lower age mean and had well-known medical risk factors, as prematurity, chronic lung disease and congenital heart disease, so it must be also included in children's vaccine.

It should be noticed that most positive patients for influenza virus, generally required oxygen therapy more often than other patients. Heart examination must be included in followup for hospitalized LRTIs patients, as the cardiac diseases were the most common comorbidity. The study of the local epidemiology of respiratory viruses, is essential yearly, for predicting epidemics and planning for preventive measures, especially for the high risk groups.
Abbreviations
RT-PCR Reverse transcription Polymerase chain reaction.
LRTIs Lower respiratory tract infection.
URTIs Upper respiratory tract infection.
ILI Influenza- like illness.
WHO World Health Organization
NPA Nasopharyngeal aspirates.
VTM Viral transport medium.
HEV Human enterovirus.
HRV Human rhinovirus.
RSV Human respiratory syncytial virus.
hMPV Human metapneumovirus. 
Flu-A Influenza-A.

Flu-B Influenza-B.

Adv Adenovirus.

PIV-1 Parainfluenza-1.

PIV-2 Parainfluenza-2.

PIV-3 Parainfluenza-3.

PIV-4 Parainfluenza-4.

$\mathrm{HBoV}$ Human bocavirus.

ICU Intensive care unit.

\section{REFERENCES}

1- A. S. Monto and K. M. Sullivan, "Acute respiratory illness in the community. Frequency of illness and the agents involved", Epidemiol. Infect., 110 (1), 145-160 (1993).

2- T. Chonmaitree, K. Revai, J. J. Grady, A. Clos, J. A. Patel, S. Nair, J. Fan and K. J. Henrickson., "Viral upper respiratory tract infection and otitis media complication in young children", Clin. Infect. Dis., 46 (6), 815-823 (2008).

3- W. C. Gruber, "The epidemiology of respiratory infections in children", Semin. Pediatr. Infect. Dis., 6 (2), 49-56 (1995).

4- S. A. Madhi and K. P. Klugman, "Acute Respiratory Infections", In: D. T. Jamison, R. G. Feachem, M. W. Makgoba, et al., Eds. Disease and Mortality in SubSaharan Africa. $2^{\text {nd }}$ Edn. Washington (DC): The International Bank for Reconstruction and Development/ The World Bank, 2006, Chapter 11.

5- B. G. Williams, E. Gouws, C. BoschiPinto, J. Bryce and C. Dye. "Estimates of world-wide distribution of child deaths from acute respiratory infections", Lancet Infect. Dis., 2 (1):25-32 (2002).

6- J. Bryce, C. Boschi-Pinto, K. Shibuya and R. E. Black, "WHO Child Health Epidemiology Reference Group. WHO estimates of the causes of death in children", Lancet, 365 (9465), 1147-1152 (2005).

7- J. S. Tregoning and J. Schwarze, "Respiratory viral infections in infants: Causes, clinical symptoms, virology, and immunology", Clin. Microbiol. Rev., 23 (1), 74-98 (2010).
8- S. Rhedin, A. Lindstrand, M. RotzénÖstlund, T. Tolfvenstam, L. Ohrmalm, M. R. Rinder, B. Zweygberg-Wirgart, A. Ortqvist, B. Henriques-Normark, K. Broliden and P. Naucler, "Clinical utility of PCR for common viruses in acute respiratory illness", Pediatrics, 133 (3), e538-e545 (2014).

9- A. M. Fendrick, A. S. Monto, B. Nightengale and M. Sarnes, "The economic burden of non-influenza-related viral respiratory tract infection in the United States", Arch. Intern. Med., 163 (4), 487-494 (2003).

10- A. T. Pavia, "Viral infections of the lower respiratory tract: Old viruses, new viruses, and the role of diagnosis", Clin. Infect. Dis., 52 Suppl 4 (Suppl 4), S284-S289. (2011).

11- C. Trucchi, C. Paganino, A. Orsi, D. Amicizia, V. Tisa, M.F. Piazza, D. Gallo, S. Simonetti, B. Buonopane, G. Icardi and F. Ansaldi, "Hospital and economic burden of influenza-like illness and lower respiratory tract infection in adults $\geq 50$ years-old", BMC Health Serv. Res., 19 (1), 585 (2019).

12- D. R. Hijano, J. Brazelton de Cardenas, G. Maron, C. D. Garner, J. A. Ferrolino, R. H. Dallas, Z. Gu and R. T. Hayden, "Clinical correlation of influenza and respiratory syncytial virus load measured by digital PCR", PLoS ONE, 14 (9), e0220908 (2019).

13- S. Drieghe, I. Ryckaert, K. Beuselinck, K. Lagrou and E. Padalko, "Epidemiology of respiratory viruses in bronchoalveolar lavage samples in a tertiary hospital", $\boldsymbol{J}$. Clin. Virol., 59 (3), 208-211 (2014).

14- C. Griffiths, S. J. Drews and D. J. Marchant, "Respiratory syncytial virus: Infection, detection, and new options for prevention and treatment", Clin. Microbiol. Rev., 30 (1), 277-319 (2017).

15- B. G. van den Hoogen, J. C. de Jong, J. Groen, T. Kuiken, R. de Groot, R. A. Fouchier and A. D. Osterhaus, "A newly discovered human pneumovirus isolated from young children with respiratory tract disease", Nat. Med., 7 (6), 719-24 (2001). 
16- C. Drosten, S. Günther, W. Preiser, S. van der Werf, H. R. Brodt, S. Becker, H. Rabenau, M. Panning, L. Kolesnikova, R. A. Fouchier, A. Berger, A. M. Burguière, J. Cinatl, M. Eickmann, N. Escriou, K. Grywna, S. Kramme, J. C. Manuguerra, S. Müller, V. Rickerts, M. Stürmer, S. Vieth, H. D. Klenk, A. D. Osterhaus, H. Schmitz and H. W. Doerr, "Identification of a novel coronavirus in patients with severe acute respiratory syndrome", $\boldsymbol{N}$. Engl. $\boldsymbol{J}$. Med., 15, 348 (20), 1967-76 (2003).

17- L. van der Hoek, K. Pyrc, M. F. Jebbink, W. Vermeulen-Oost, R. J. Berkhout, K. C. Wolthers, P. M. Wertheim-van Dillen, J. Kaandorp, J. Spaargaren and B. Berkhout, "Identification of a new human coronavirus", Nat. Med., 10 (4), 368-73 (2004).

18- N. Bastien, K. Brandt, K. Dust, D. Ward and $\mathrm{Y} . \mathrm{Li}$, "Human bocavirus infection, Canada", Emerg. Infect. Dis., 12 (5), 84850 (2006).

19- X. W. Qu, Z. J. Duan, Z. Y. Qi, Z. P. Xie, H. C. Gao, W. P. Liu, C. P. Huang, F. W. Peng, L. S. Zheng and Y. D. Hou, "Human bocavirus infection, People's Republic of China", ibid., 13 (1), 165-8 (2007).

20- P. C. Woo, S. K. Lau, Y. Huang, H. W. Tsoi, K. H. Chan and K. Y. Yuen, "Phylogenetic and recombination analysis of coronavirus HKU1, a novel coronavirus from patients with pneumonia", Arch. Virol., 150 (11), 2299-311 (2005).

21- A. M. Zaki, S. van Boheemen, T. M. Bestebroer, A. D. Osterhaus and R. A. Fouchier, "Isolation of a novel coronavirus from a man with pneumonia in Saudi Arabia", N. Engl. J. Med., 8, 367 (19), 1814-20 (2012).

22- B. P. José, P. A. Camargos, Á. A. Cruz Filho and A. Corrêa Rde, "Diagnostic accuracy of respiratory diseases in primary health units", Rev. Assoc. Med. Bras., 60 (6), 599-612 (2014).

23- A. F. Dugas, A. Valsamakis, M. R. Atreya, K. Thind, P. Alarcon Manchego, A. Faisal, C. A. Gaydos and R. E. Rothman, "Clinical diagnosis of influenza in the ED", Am. J. Emerg. Med., 33 (6), 770-775 (2015).
24- B. A. Pinsky and R. T. Hayden, "CostEffective Respiratory Virus Testing", $\boldsymbol{J}$. Clin. Microbiol., 57 (9), e00373-19 (2019).

25- G. A. Weinberg, D. D. Erdman, K. M. Edwards, C. B. Hall, F. J. Walker, M. R. Griffin, B. Schwartz and New Vaccine Surveillance Network Study Group, "Superiority of reverse-transcription polymerase chain reaction to conventional viral culture in the diagnosis of acute respiratory tract infections in children", $\boldsymbol{J}$. Infect. Dis., 189 (4), 706-710 (2004).

26- S. Esposito, A. Mencacci, E. Cenci, B. Camilloni, E. Silvestri and N. Principi, "Multiplex Platforms for the Identification of Respiratory Pathogens: Are They Useful in Pediatric Clinical Practice?", Front. Cell. Infect. Microbiol., 9, 196 (2019).

27- O. Clerc and G. Greub, "Routine use of point-of-care tests: usefulness and application in clinical microbiology", Clin. Microbiol. Infect., 16 (8), 1054-1061 (2010).

28- T. Heikkinen, J. Marttila, A. A. Salmi and O. Ruuskanen, "Nasal swab versus nasopharyngeal aspirate for isolation of respiratory viruses", J. Clin. Microbiol., 40 (11), 4337-4339 (2002).

29- T. Wardlaw, P. Salama, E. W. Johansson and E. Mason, "Pneumonia: The leading killer of children", Lancet, 368 (9541), 1048-1050 (2006).

30- C. B. Del Mar, P. Glasziou and BMJ Publishing Group, "Upper respiratory tract infection", Am. Fam. Physician., 66 (11), 2143-2144 (2002).

31- C. Del Mar and P. Glasziou, "Upper respiratory tract infection", Clin. Evid., 9, 1701-1711 (2003).

32- H. S. Huang, C. L. Tsai, J. Chang, T. C. Hsu, S. Lin and C. C. Lee, "Multiplex PCR system for the rapid diagnosis of respiratory virus infection: systematic review and meta-analysis", Clin.

Microbiol. Infect., 24 (10), 1055-1063 (2018).

33- G. Parrott, T. Kinjo, D. Nabeya, A. Uehara, S. Nahar, K. Miyagi, S. Haranaga, M. Tateyama and J. Fujita, "Evaluation of 
Anyplex $^{\mathrm{TM}}$ II RV16 and RB5 real-time RT-PCR compared to Seeplex® RV15 OneStep ACE and PneumoBacter ACE for the simultaneous detection of upper respiratory pathogens", J. Infect. Chemother., 23 (12), 859-861. (2017).

34- S. Esposito, A. Zampiero, S. Bianchini, A. Mori, A. Scala, C. Tagliabue, C.S. Sciarrabba, E. Fossali, A. Piralla and N. Principi, "Epidemiology and clinical characteristics of respiratory infections due to adenovirus in children living in Milan, Italy, during 2013 and 2014", PLoS ONE, 11 (4), e0152375 (2016).

35- E. N. Antonova, C. E. Rycroft, C. S. Ambrose, $\mathrm{T}$ Heikkinen and $\mathrm{N}$ Principi, "Burden of paediatric influenza in Western Europe: A systematic review", BMC Public Health, 12, 968 (2012).

36- T. B. Kwofie, Y.A. Anane, B. Nkrumah, A. Annan, S. B. Nguah and M. Owusu, "Respiratory viruses in children hospitalized for acute lower respiratory tract infection in Ghana", Virol. J., 9, 78 (2012).

37- A. M. Fattouh, Y. A. Mansi, M. G. ElAnany, A. A. El-Kholy and H. M. ElKaraksy, "Acute lower respiratory tract infection due to respiratory syncytial virus in a group of Egyptian children under 5 years of age", Ital. J. Pediatr., 37, 14 (2011).

38- M. Imakita, K. Shiraki, C. Yutani and H. Ishibashi-Ueda, "Pneumonia caused by rhinovirus", Clin. Infect. Dis., 30 (3), 611 612 (2000).

39- N. G. Papadopoulos, I. Christodoulou, G. Rohde, I. Agache, C. Almqvist, A. Bruno, S. Bonini, L. Bont, A. Bossios, J. Bousquet, F. Braido, G. Brusselle, G.W. Canonica, K.H. Carlsen, P. Chanez, W.J. Fokkens, M. Garcia-Garcia, M. Gjomarkaj, T. Haahtela, S.T. Holgate, S.L. Johnston, G. Konstantinou, M. Kowalski, A. Lewandowska-Polak, K. Lødrup-Carlsen, M. Mäkelä, I. Malkusova, J. Mullol, A. Nieto, E. Eller, C. Ozdemir, P. Panzner, T. Popov, S. Psarras, E. Roumpedaki, M. Rukhadze, A. Stipic-Markovic, A. Todo Bom, E.
Toskala, P. van Cauwenberge, C. van Drunen, J.B. Watelet, M. Xatzipsalti, P. Xepapadaki and T. Zuberbier, "Viruses and bacteria in acute asthma exacerbations--a $\quad \mathrm{GA}^{2} \quad$ LEN-DARE systematic review", Allergy, 66 (4), 458468 (2011).

40- M. Khadadah, "The cost of asthma in Kuwait", Med. Princ. Pract., 22 (1), 87-91 (2013).

41- T. J. Meerhoff, A. Simaku, D. Ulqinaku, L. Torosyan, N. Gribkova, V. Shimanovich, G. Chakhunashvili, I. Karseladze, A. Yesmagambetova, A. Kuatbayeva, Z. Nurmatov, D. Otorbaeva, E. Lupulescu, O. Popovici, E. Smorodintseva, A. Sominina, O. Holubka, O. Onyshchenko, C. S. Brown and D. Gross, "Surveillance for severe acute respiratory infections (SARI) in hospitals in the WHO European region - An exploratory analysis of risk factors for a severe outcome in influenza-positive SARI cases", BMC Infect. Dis., 15, 1 (2015).

42- M. A. Al-Shehri, A. Sadeq and K. Quli, "Bronchiolitis in Abha, Southwest Saudi Arabia: viral etiology and predictors for hospital admission", West Afr. J. Med., 24 (4), 299-304 (2005).

43- S. A. Uduman, M. K. Ijaz, J. Kochiyil, T. Mathew and M. K. Hossam, "Respiratory syncytial virus infection among hospitalized young children with acute lower respiratory illnesses in $\mathrm{Al}$ Ain, UAE", J. Commun. Dis., 28 (4), 245-252 (1996).

44- Y. Yan, L. Huang, M. Wang, W. Ji, C. Zhu and Z. Chen, "Clinical and epidemiological profiles including meteorological factors of low respiratory tract infection due to human rhinovirus in hospitalized children", Ital. J. Pediatr., 43 (1), 23 (2017).

45- M. Al-Turab, W. Chehadeh, F. Al-Mulla and W. Al-Nakib, "Human metapneumovirus in patients with respiratory tract infection in Kuwait", J. Med. Virol., 83 (10), 1811-1817 (2011).

46- J. S. Casalegno, M. Ottmann, M. B. Duchamp, V. Escuret, G. Billaud, E. 
Frobert, F. Morfin and B. Lina, "Rhinoviruses delayed the circulation of the pandemic influenza A (H1N1) 2009 virus in France", Clin. Microbiol. Infect., 16 (4), 326-329 (2010).

47- N. Schnepf, M. Resche-Rigon, A. Chaillon, et al., "High burden of noninfluenza viruses in influenza-like illness in the early weeks of H1N1v epidemic in France", PLoS ONE, 6 (8), e23514 (2011).

48- A. Piralla, F. Rovida, G. Campanini, V. Rognoni, A. Marchi, F. Locatelli and G. Gerna, "Clinical severity and molecular typing of human rhinovirus $\mathrm{C}$ strains during a fall outbreak affecting hospitalized patients", J. Clin. Virol., 45 (4), 311-317 (2009).

49- N. Renwick, B. Schweiger, V. Kapoor, Z. Liu, J. Villari, R. Bullmann, R. Miething, T. Briese and W. I. Lipkin, "A recently identified rhinovirus genotype is associated with severe respiratory-tract infection in children in Germany", $\boldsymbol{J}$. Infect. Dis., 196 (12), 1754-1760 (2007).

50- A. Wisdom, A. E. Kutkowska, E. C. McWilliam Leitch, E. Gaunt, K. Templeton, H. Harvala and P. Simmonds, "Genetics, recombination and clinical features of human rhinovirus species $\mathrm{C}$ (HRV-C) infections; interactions of HRV$\mathrm{C}$ with other respiratory viruses", PLoS ONE, 4 (12), e8518 (2009).

51- J. Longtin, A. Marchand-Austin, A. L. Winter, S. Patel, A. Eshaghi, F. Jamieson, D. E. Low and J. B. Gubbay, "Rhinovirus outbreaks in long-term care facilities, Ontario, Canada", Emerg. Infect. Dis., 16 (9), 1463-1465 (2010).

52- E. K. Miller, N. Khuri-Bulos, J. V. Williams, A. A. Shehabi, S. Faouri, I. Al Jundi, Q. Chen, L. Heil, Y. Mohamed, L. L. Morin, A. Ali and N. B. Halasa, "Human rhinovirus $\mathrm{C}$ associated with wheezing in hospitalised children in the Middle East", J. Clin. Virol., 46 (1), 85-89 (2009).

53- T. Briese, N. Renwick, M. Venter, R. G. Jarman, D. Ghosh, S. Köndgen, S. K. Shrestha, A. M. Hoegh, I. Casas, E. V. Adjogoua, C. Akoua-Koffi, K. S. Myint,
D. T. Williams, G. Chidlow, R. van den Berg, C. Calvo, O. Koch, G. Palacios, V. Kapoor, J. Villari, S. R. Dominguez, K. V. Holmes, G. Harnett, D. Smith, J. S. Mackenzie, H. Ellerbrok, B. Schweiger, K. Schønning, M. S. Chadha, F. H. Leendertz, A. C. Mishra, R. V. Gibbons, E. C. Holmes and W. I. Lipkin, "Global distribution of novel rhinovirus genotype", Emerg. Infect. Dis., 14 (6), 944-947 (2008).

54- S. Yusuf, G. Piedimonte, A. Auais, G. Demmler, S. Krishnan, P. Van Caeseele, R. Singleton, S. Broor, S. Parveen, L. Avendano, J. Parra, S. Chavez-Bueno, T. Murguía De Sierra, E. A. Simoes, S. Shaha and R. Welliver, "The relationship of meteorological conditions to the epidemic activity of respiratory syncytial virus", Epidemiol. Infect., 135 (7), 10771090 (2007).

55- S. E. Coffin, K. Leckerman, R. Keren, M. Hall, R. Localio and T. E. Zaoutis, "Oseltamivir shortens hospital stays of critically ill children hospitalized with seasonal influenza: a retrospective cohort study", Pediatr. Infect. Dis J., 30 (11), 962-966 (2011).

56- M. K. Iwane, M. M. Prill, X, Lu, E. K. Miller, K. M. Edwards, C. B. Hall, M. R. Griffin, M. A. Staat, L. J. Anderson, J. V. Williams, G. A. Weinberg, A. Ali, P. G. Szilagyi, Y. Zhu and D. D. Erdman, "Human rhinovirus species associated with hospitalizations for acute respiratory illness in young US children", J. Infect. Dis., 204 (11), 1702-1710 (2011).

57- M. J. El-Hajje, F. Moulin, N. de Suremain, E. Marc, C. Cosnes-Lambe, C. PonsCatalano, M. Lorrot, M. Chalumeau, F. Rozenberg, J. Raymond, P. Lebon and D. Gendrel, "Respiratory syncytial virus in hospitalized children. A 3-year study", Presse. Med., 37 (1 Pt 1), 37-43 (2008).

58- B. Zheng, Y. Zhang, H. He, E. Marinova, K. Switzer, D. Wansley, I. Mbawuike and S. Han, "Rectification of age-associated deficiency in cytotoxic $\mathrm{T}$ cell response to influenza A virus by immunization with immune complexes", J. Immunol., 179 (9), 6153-6159 (2007). 
59- D. A. Queiróz, E. L. Durigon, V.F. Botosso, B. Ejzemberg, S. E. Vieira, J. R. Mineo, C. Yamashita, N. Hein, C. L. Lopes, A. L. Cacharo and K. E. Stewien, "Immune response to respiratory syncytial virus in young Brazilian children", Braz. J. Med. Biol. Res., 35 (10), 1183-1193 (2002).

60- T. Juvén, J. Mertsola, P. Toikka, R. Virkki, M. Leinonen and O. Ruuskanen, "Clinical profile of serologically diagnosed pneumococcal pneumonia", Pediatr. Infect. Dis. J., 20 (11), 1028-1033 (2001).

61- G. D. Hussey, P. Apolles, Z. Arendse, J. Yeates, A. Robertson, G. Swingler and $\mathrm{H}$. J. Zar, "Respiratory syncytial virus infection in children hospitalised with acute lower respiratory tract infection", $\boldsymbol{S}$. Afr. Med. J., 90 (5), 509-512 (2000).
62- E. Rowlinson, E. Dueger, A. Mansour, N. Azzazy, H. Mansour, L. Peters, S. Rosenstock, S. Hamid, M.M. Said, M. Geneidy, M. Abd Allah and A. Kandeel, "Incidence and etiology of hospitalized acute respiratory infections in the Egyptian Delta", Influenza Other Respir. Viruses, 11(1), 23-32 (2017).

63- A. Hatem, S. Mohamed, U. E. Abu Elhassan, E. A. M. Ismael, M. S. Rizk, A. El-Kholy and M. El-Harras, "Clinical characteristics and outcomes of patients with severe acute respiratory infections (SARI): results from the Egyptian surveillance study 2010-2014", Multidiscip. Respir. Med., 1,14, 11 (2019). 


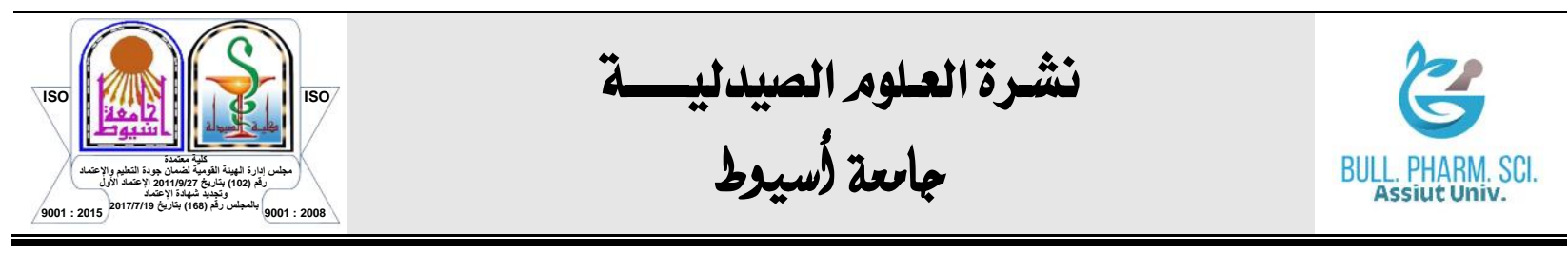

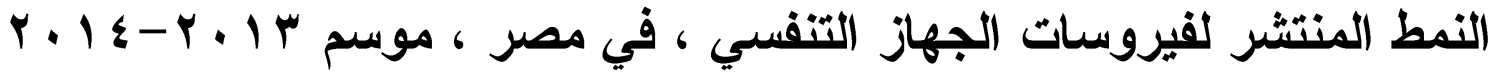 وائل حامد رشدي' - أمل محمد نجيب' - إبر اهيم السيد - يارا ابر اهيم شامخغ}

'دكتوراه في الكيمياء الحيوية والفيروسات الجزيئية ، رئيس قسم زراعة الأنسجة وعزل الفيروسات ، المعامل

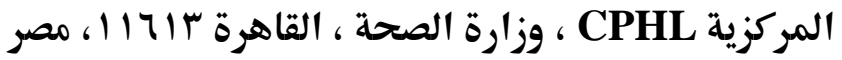

'ماجستير في الباثولوجيا الإكلينيكية ، رئيس قسم الفيروسات، المعامل المركزيـة CPHL ، وزارة الصحة ،

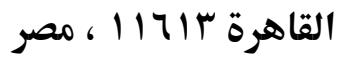

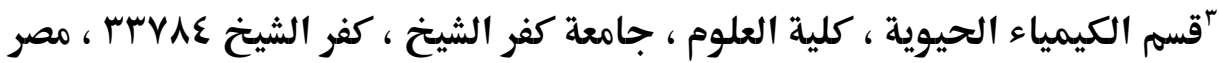

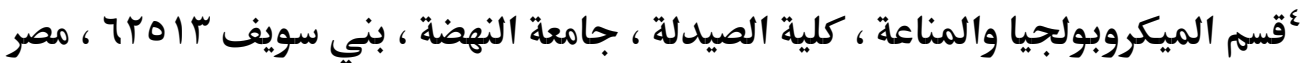
ققسم الفيروسات ، المركز المصري للأبحاث والطب التجديدي ECRRM ، القاهرة V| 10 ، مصر

نبذة مختصرة: الالتهابات الفيروسية في الجهاز التنفسي السفلي LRTIs و العلوي ، URTIs مــن أكثـر

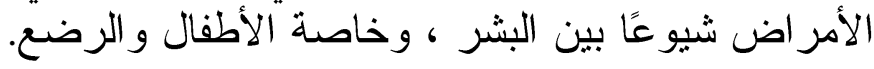

أهداف البحث: ثقدم هذه الدر اسة الدليل على استخدام طريقة تفاعل البوليميراز المتسلسل المتعـدد كأداة مفيدة في تصنيف النمط المنتشر لفيروسات الجهاز التفسي لتحديد وابتكار علاجــات ولقاحـات جديدة.

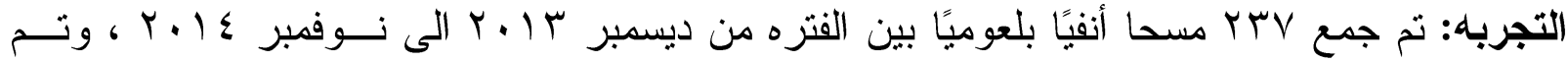

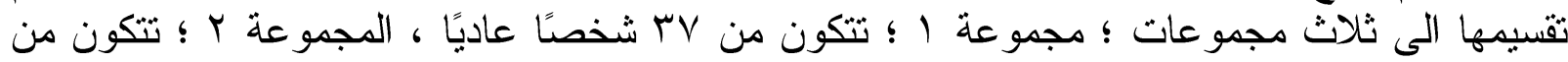

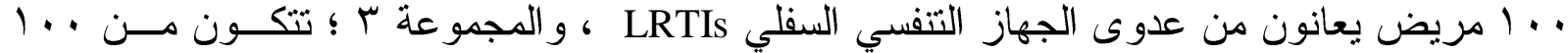

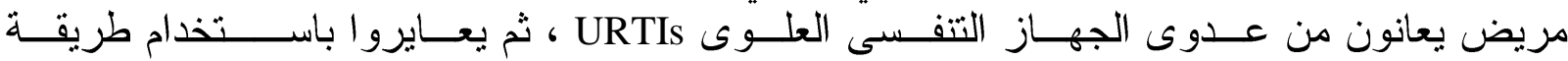
.Multiplex RT-PCR

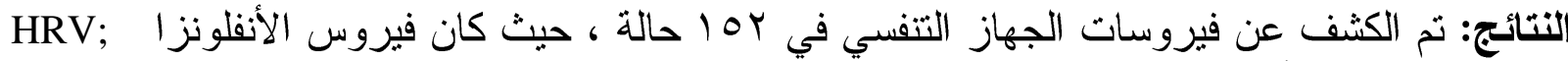

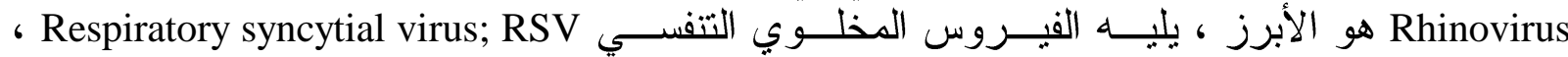

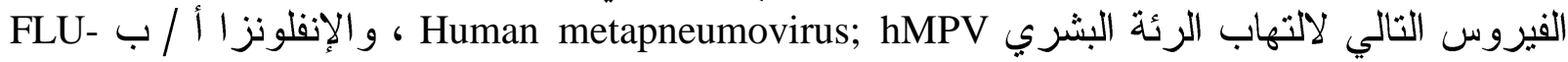

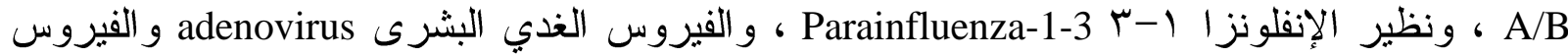

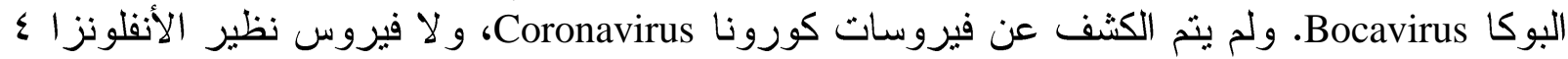

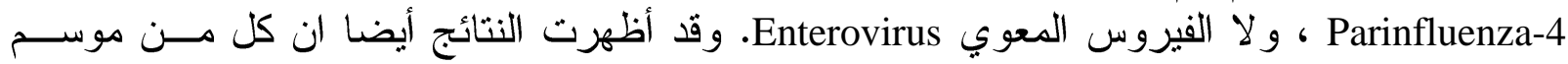
و عمر المرضى يؤثر على معدل اكتشاف نتائج التحاليل. 